\title{
Do Elderly Patients Call 911 When Presented with Clinical Scenarios Suggestive of Acute Stroke? A Cross-Sectional Study
}

\author{
Diego Caruso ${ }^{a}$ Manuel Perez Akly ${ }^{b}$ Pablo Daniel Costantini ${ }^{b}$ \\ Sebastian Fridman ${ }^{b}$ Maria Martha Esnaola ${ }^{b}$ \\ Departments of ${ }^{a}$ Internal Medicine and ${ }^{b}$ Neurology, Hospital Dr. César Milstein associated with University of \\ Buenos Aires, Buenos Aires, Argentina
}

\section{Key Words}

Stroke · Elderly · Knowledge · Emergency medical services ·

Awareness

\begin{abstract}
Background and Purpose: Among patients with acute stroke symptoms, delay in hospital admission is the main obstacle for the use of thrombolytic therapy and other interventions associated with decreased mortality and disability. The primary aim of this study was to assess whether an elderly clinical population correctly endorsed the response to call for emergency services when presented with signs and symptoms of stroke using a standardized questionnaire. Methods: We performed a cross-sectional study among elderly out-patients ( $\geq 60$ years) in Buenos Aires, Argentina randomly recruited from a government funded health clinic. The correct endorsement of intention to call 911 was assessed with the Stroke Action Test and the cut-off point was set at $\geq 75 \%$. Knowledge of stroke and clinical and socio-demographic indicators were also collected and evaluated as predictors of correct endorsement using logistic regression. Results: Among 367 elderly adults, 14\% correctly endorsed intention to call 911. Presented with the most typical signs and symptoms, only $65 \%$ reported that they would call an
\end{abstract}

ambulance. Amaurosis Fugax was the symptom for which was called the least (15\%). On average, the correct response was chosen only $37 \%$ of the time. Compared to lower levels of education, higher levels were associated to correctly endorsed intention to call 911 (secondary School adjusted OR $3.53,95 \% \mathrm{Cl} 1.59-7.86$ and Tertiary/University adjusted OR $3.04,95 \% \mathrm{Cl} 1.12-8.21)$. Conclusions: These results suggest the need to provide interventions that are specifically designed to increase awareness of potential stroke signs and symptoms and appropriate subsequent clinical actions.

(c) 2015 S. Karger AG, Basel

\section{Introduction}

Nine million strokes occur each year worldwide and it is the fourth global leading cause of death. Within western countries, the incidence of stroke is only exceeded by acute myocardial infarction and cancer [1]. In addition to mortality, stroke is also the leading cause of long-term disability, with a global disability-adjusted life years of 1,484 per 100,000 persons leading to high costs for global public health [2]. Current information on stroke incidence and prevalence are lacking in Argentinian National Agencies. The Argentinian in-hospital mortality rate is

\section{KARGER 125}

(c) 2015 S. Karger AG, Base

1015-9770/15/0392-0087\$39.50/0
Diego Caruso, Staff Physician

Internal Medicine Department

Hospital Dr. César Milstein

La Rioja 951, Buenos Aires, C1221ACI (Argentina)

E-Mail diecaruso@ hotmail.com 
7.6\% according to the ReNACer study [3]. Despite the reduction in mortality stroke rates in the last years, the present situation still calls for action.

Since 1995 researchers have consistently shown that vascular reperfusion treatment with thrombolytic drugs or mechanical devices [4-7] effectively reduce stroke-related long-term disability. The essential characteristics of these treatments include a narrow therapeutic time window and the availability of an emergency medical service consultation. In the Argentinean ReNACer study, only $1.05 \%$ of the patients received thrombolytic therapy [3], which was lower than in a recent study of 712,433 ischemic strokes in adult persons from the United States (1.9\%) [8]. The major reasons for not using thrombolytic therapy in patients with stroke are patient delay in seeking stroke treatment and clinical delay within the emergency department (ED) [9-11].

In an Argentinian registry of stroke signs and symptoms, $34.1 \%$ did not spontaneously mention any of the warning signs [12]. Moreover, studies across various countries show that early stroke warning signs and risk factors knowledge are not recognized by patients [13-18]. Even stroke survivors may not be able to identify stroke symptoms and risk factors [19]. Patient delay in seeking stroke treatment may be due to individuals not recognizing warning symptoms or signs of stroke.

In the present study we used a standardized questionnaire describing current or impending stroke symptoms to assess the prevalence of correct endorsement to response to call emergency services among an elderly clinical population in Buenos Aires, Argentina as well as predictors of correct endorsement. Results from this study will be used to inform tailored interventions for this highly at risk population.

\section{Methods}

\section{Study Population and Survey Design}

We performed a cross-sectional study from July to August 2013. We recruited participants from the Hospital Cesar Milstein, one of the three out-patient centers sponsored by the National Institute of Social Services for Retirees and Pensioners (INSSJP) in Buenos Aires. INSSJP is a government funded social insurance program and serves 4.5 million elderly patients in the country; approximately 300,000 live in Buenos Aires, Argentina. We randomly sampled patients stratified by medical specialty clinics $(n=7)$ covering all timetables, all specialties and weighted by the proportion of consultations per month, to ensure a representative number of each stratum. We included patients with a scheduled health care appointment and excluded patients who were unable to complete the study protocol due to language barriers, hearing/visual impairment or were INSSJP employees.
The study protocol was approved by the institutional review board. All patients provided verbal consent after reading the patient information sheet and prior to subject participation. All data were obtained anonymously.

\section{Primary Outcome}

Our primary outcome was 'correct endorsement of calling 911' defined as the acknowledgment of the need to call for emergency services (911) assessed with the Stroke Action Test (STAT) [20]. The STAT, a valid and reliable instrument for assessing correct responses to individual stroke symptoms, consists of 28 close-ended items. Twenty one items describe common stroke-warning signs and 7 describe non-stroke warning signs. For each item, there are 4 possible responses: call 911; go to the emergency room; wait $1 \mathrm{~h}$ prior to deciding next action; and wait 1 day prior to deciding next action. The STAT is scored by counting how many times the respondent selected the correct answer (call 911) for stroke symptoms (21 items) and modeled as a continuous variable. We modeled the STAT responses as a dichotomous variable. First we coded the response as ' 1 ' if they chose to call 911 and ' 0 ' for all other responses and then we considered having correctly endorsed $\geq 15$ items as a valid cut-off point as previously described [20].

The instrument was originally developed in English and we translated it into Spanish and adapted it using standardized methodology [21]. An important cultural adaptation example included adding to the response 'go to the emergency room' the option 'or call or go to see the doctor'. In Buenos Aires, 911 responses in need of acute care are commonly delayed; therefore, patients frequently call or go directly to their health care provider.

\section{Predictors of Interest}

To assess knowledge about risk factors and warning signs for stroke we asked the participants to answer the question: 'Please name all the factors you are aware of that are related to stroke'. We then compared their list with a list of 13 items (risk factors $n=8$, warning signs $n=5$ ) as provided by the American Heart Association (AHA) [22]. For each item that agreed with the AHA list, we assigned 1 point for a maximum of 13 points. We modeled these two variables as categorical as follows: $0,1,2$, and $\geq 3$ factors or signs. To assess comorbidities, health behaviors, and education levels we used the National Survey of Risk Factors 2005 [23]. To assess the socio-economic status we used the 6 durables household ownerships extracted from the European Society for Opinion and Marketing Research (ESOMAR) survey, validated among Argentineans [24, 25].

\section{Statistical Analysis}

Based on our recruitment of 367 patients, we estimated that we would have a $95 \%$ confidence interval around for the following proportions for 33\% of (28-38) and 50\% (45-55).

We assessed bivariate comparisons using appropriate parametric and non-parametric statistical tests. We developed four unadjusted and adjusted multivariate logistic regression models to examine the association between a priori specified predictors and correct endorsement of calling 911: Model 1) knowledge of stroke risk factors and stroke warning signs; Model 2) comorbidities (hypertension, diabetes mellitus, dyslipidemia, and previous stroke; Model 3) health behaviors (flu vaccination, smoking, alcohol consumption), and Model 4) demographic and socio-economic factors (age, gender, socioeconomic status, and education). 
Post-hoc we assessed the interaction between knowledge and education level by introducing an interaction term (knowledge + education + knowledge $*$ education) in the logistic regression model. We used 0.05 as the statistical level and data analysis was performed using $\mathrm{R}$ commander version 3.0.

\section{Results}

\section{Population}

Of the 527 patients sampled from the patient roster, 10 did not meet the inclusion criteria because they were younger than 60,87 patients did not attend the targeted appointment, and 63 refused to answer or completed less than half of the required data. Finally, 367 patients were included in the analysis (see fig. 1).

\section{Demographics}

Consistent with the demographics of our source population, respondents were predominantly older (median age 72.0 years (IQR 63-81)) women (70\%) [25], with high prevalence of stroke risk factors: hypertension (60\%), dyslipidemia (52\%) and diabetes (27.5\%). Consistent with the age of the cohort, university training was uncommon in the forties, the large majority of patients achieved either a primary or secondary education: 165 (45\%) completed primary school, 109 (30\%) completed high school, and 61 (16\%) had at least some university training.

\section{Prevalence of Correctly Endorsing Intention to Call 911}

When provided with clinical scenarios consistent with stroke, $14 \%$ (95\% CI 11-18) of the study population correctly endorsed the intention of calling 911, using a threshold of responding appropriately to $75 \%$ of the questions. On average the correct response for stroke symptoms was chosen $37 \%$ of the time in contrast with $50 \%$ for cardiac symptoms. In general, stroke symptoms that involved motor function and cardiac symptoms were mostly recognized as a clinical scenario to call 911 (fig. 2). Symptoms that included speech and visual problems were least recognized.

\section{Knowledge: Stroke Risk Factors}

Of the 8 AHA stroke risk factors, $70 \%$ of patients were able to identify at least one and $0 \%$ identified all 8 . The most commonly identified were hypertension (46\%), dyslipidemia (28\%), smoking (24\%), and diabetes (13\%), see table 1 .

Do Elderly Patients Call 911 in Acute Stroke?

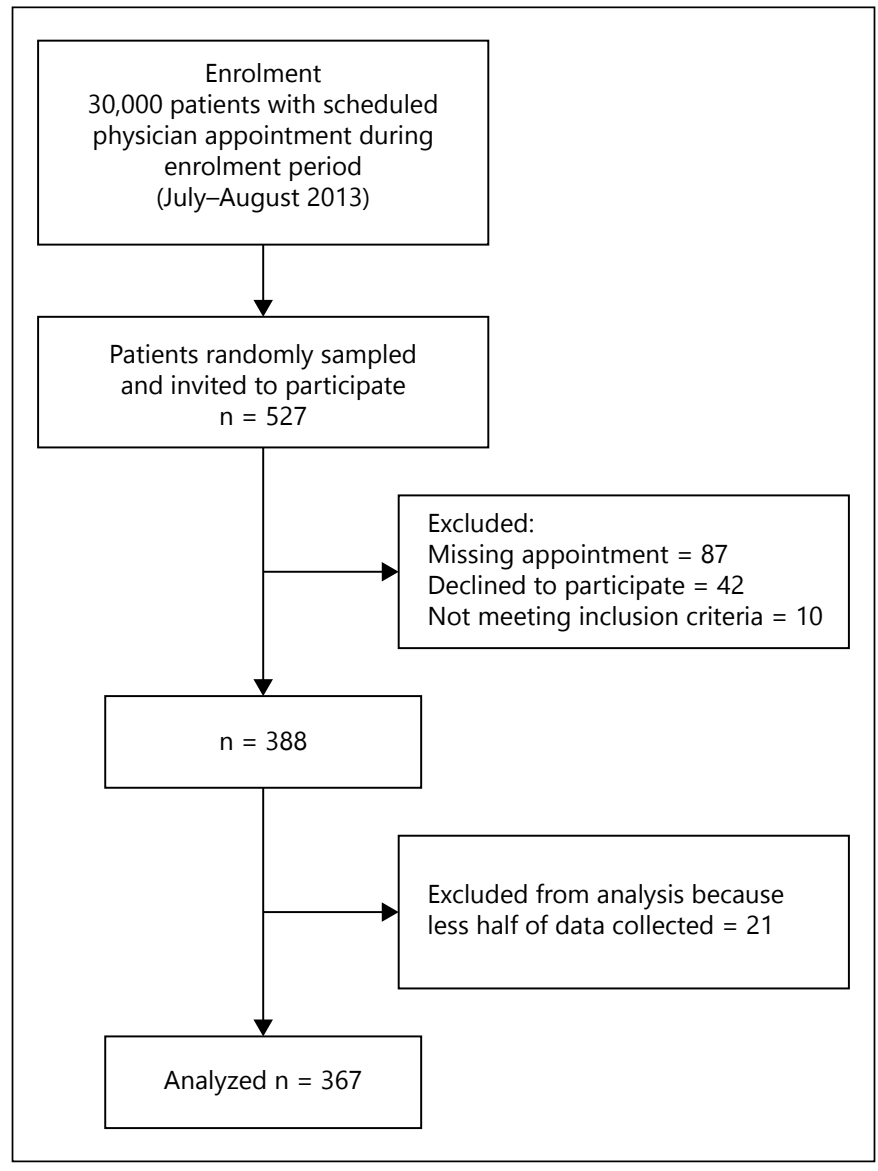

Fig. 1. Flow chart.

\section{Knowledge: Stroke Warning Signs}

Of the 5 warning signs for stroke, $70 \%$ of patients were able to name at least one warning sign, and 0\% was able to name all 5. The most commonly identified were headache $(35 \%)$, sudden unilateral weakness or numbness of the face, arm or leg (32\%), speech problems or sudden confusion $(25 \%)$, sudden trouble seeing in one or both eyes $(10 \%)$, see table 1 .

\section{Predictors of Correctly Endorsing 911 Calls}

Having more knowledge compared to no knowledge of stroke risk factors and stroke warning signs was associated with increased probability of correctly endorsing calling 911; however, they were not statistically significant, see table 2. Most comorbidities (except dyslipidemia) and health behaviors were associated with decreased probability of correctly endorsing calling 911; however, they were not statistically significant, see table 2. Younger age, higher socio-economic status, and higher educational levels were associated with a higher 
Fig. 2. Comparative rate of response between stroke and cardiac situations items in STAT questionnaire to call 911. In the vertical axis percentage of correct endorsement for calling 911. In the horizontal axis number of question of STAT questionnaire. Gray background of the figure: average of correct endorsement percentage for stroke scenarios $(37 \%)$ and cardiac scenarios $(51 \%)$.

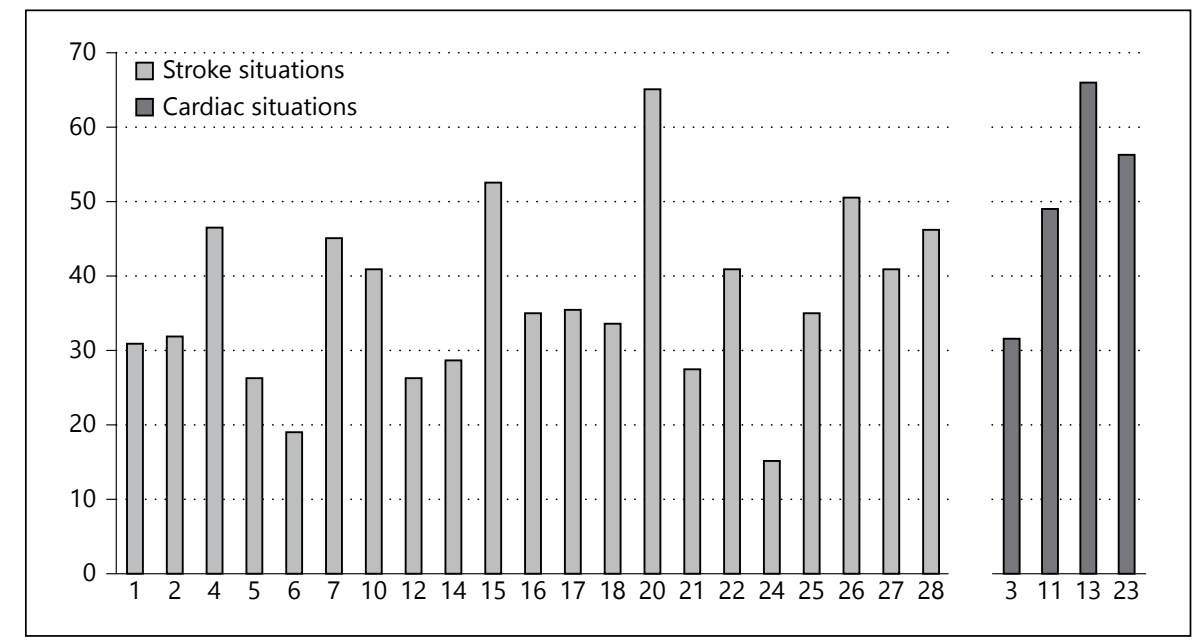

Table 1. Baseline characteristics of 367 patients surveyed for adequate recognition of stroke warning signs

\begin{tabular}{|c|c|c|c|c|c|}
\hline Demographics & & & Health behaviors & & \\
\hline Age, median (IQR) & $72(9)$ & & Flu vaccine & 194 & 53.1 \\
\hline Male sex & 108 & 29.4 & Current smoking & 37 & 10 \\
\hline Socioeconomic status & & & Alcohol consumption & 154 & 42.0 \\
\hline Low & 111 & 30.2 & Binge drinkers & 5 & 1.4 \\
\hline Educational level & & & 0 & 99 & 27.0 \\
\hline Primary level or incomplete & 141 & 38.4 & 1 & 115 & 31.3 \\
\hline Secondary level & 165 & 45.0 & 2 & 96 & 26.2 \\
\hline Tertiary or universitary & 61 & 16.6 & $\geq 3$ & 57 & 15.5 \\
\hline Comorbidities & & & Total score adjust categorical & & \\
\hline Ever smoke & 203 & 55.3 & 2 & 81 & 22.1 \\
\hline Current smoking & 37 & 10 & $\geq 3$ & 70 & 19.1 \\
\hline Alcohol consumption & 154 & 42.0 & & & \\
\hline Binge drinkers & 5 & 1.4 & & & \\
\hline
\end{tabular}

probability of correctly endorsing calling 911 but only educational level was statistically significant; secondary school vs. primary (OR 3.53, 95\% CI 1.59-7.86) and tertiary/university education vs. primary (OR 3.04, 95\% CI $1.12-8.21)$. We found a statistically significant interaction between knowledge and education levels on correctly endorsing calling 911 (all p's < 0.05); patients with a higher-level of education and higher stroke knowledge were more likely to correctly endorse calling 911, see table 2 .

\section{Discussion}

Our study showed that in a general clinic population, patients largely do not endorse calling 911 for symptoms of stroke.

Of 367 elderly patients, only $14 \%$ responded correctly to $75 \%$ of questions and only $1.6 \%$ of patients answered all questions correctly. In contrast, our data shows that there is greater awareness of situations to call 911 for cardiac symptoms. This suggests that a strong public health
90 
Table 2. Four separate logistic regression models examining knowledge, comorbidities, health behaviors and socio demographic characteristics

\begin{tabular}{|c|c|c|c|c|}
\hline $\begin{array}{l}\text { STAT score } \\
<16(\%) \\
(\mathrm{n}=314)\end{array}$ & $\begin{array}{l}\text { STAT score } \\
\geq 16(\%) \\
(\mathrm{n}=53)\end{array}$ & $\begin{array}{l}\text { OR } \\
(95 \% \mathrm{CI})\end{array}$ & $\begin{array}{l}\mathrm{p} \\
\text { value }\end{array}$ & $\begin{array}{l}\text { Adjusted OR } \\
(95 \% \mathrm{CI})\end{array}$ \\
\hline
\end{tabular}

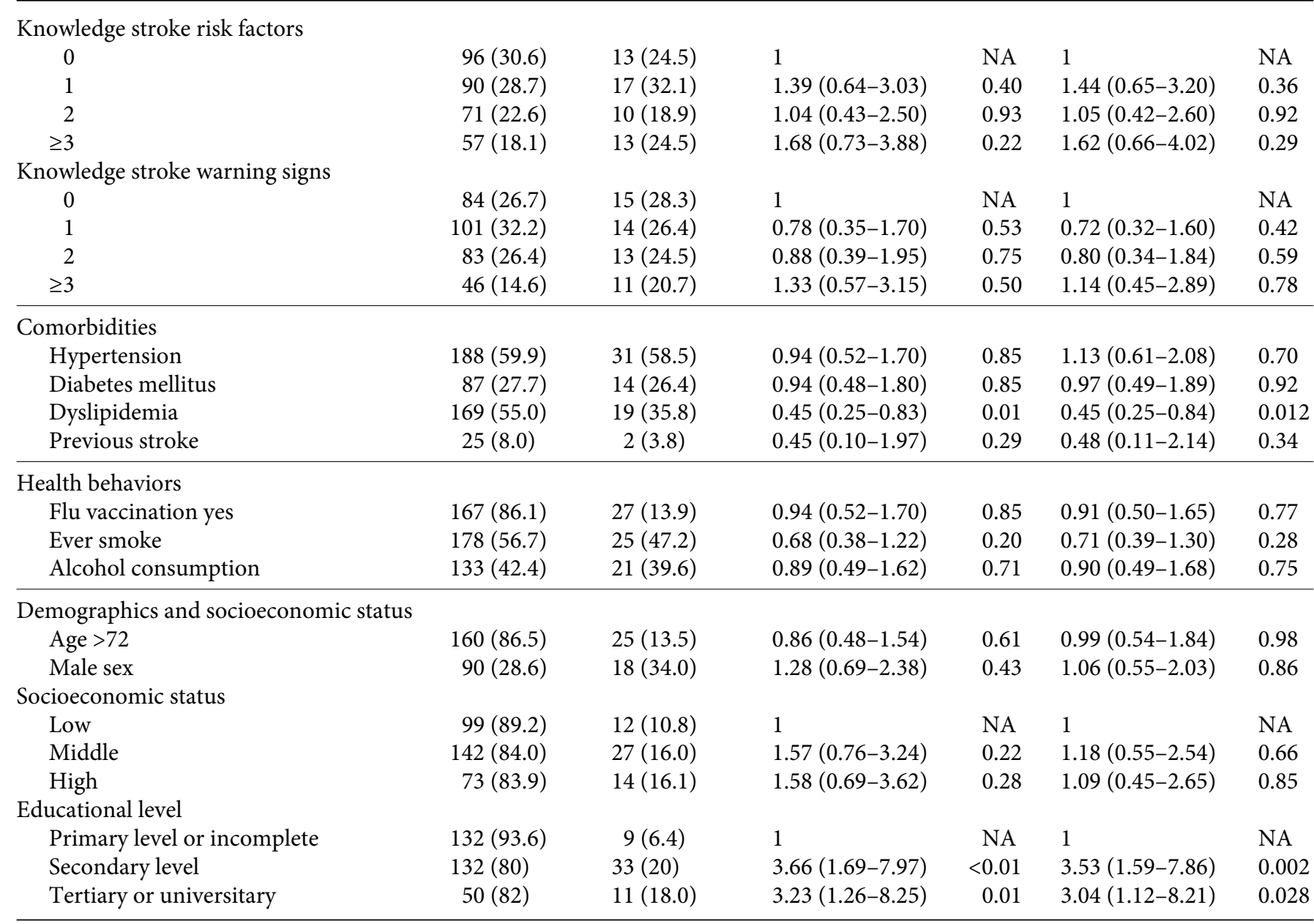

Model 1: knowledge of stroke risk factors and stroke warning signs; Model 2: comorbidities (hypertension, diabetes mellitus, dyslipidemia, and previous stroke; Model 3: health behaviors (flu vaccination, smoking, alcohol consumption), and Model 4: demographic and socio-economic factors (age, gender, socioeconomic status, and education).

effort is required to educate patients about the warning signs and symptoms of an impending, acute stroke.

This study unmasks an oversight of stroke risk factors (RF) and warning signs (WS). $30 \%$ of patients could not identify a single symptom suggestive of stroke. We found no association between knowing the risk factors or warning signs and appropriately endorsing calling $911[18$, 26].

These results demonstrate that specific knowledge of 'what is the appropriate behavior against stroke warning signs' is related to the educational levels and is not related to any of the predictors tested in this study.

When presented with symptoms of stroke, most patients over 60 years did not appropriately acknowledge the need to activate emergency services. The symptom that was least recognized was amaurosis fugax, which was present only in 15\%; this is similar to what other studies have found [26]. Extrapolating these data to patients insured by INSSJP from Buenos Aires would suggest that 270,000 people might not be able to identify early symptoms of stroke. 
The disregard of stroke risk factors, warning signs and appropriate behavior toward signs of acute stroke are consistent with previous studies [13,27].

The only previous study by Lylyk et al. in the general population was a telephone survey, which showed similar prevalence results for knowledge of Risk Factors and Warning Signs, but they did not ask about calling for emergency services [12].

The mayor strengths of this study included validated instruments and random sample of a complete population-based study to prevent selection bias. Rigorous training and ascertaining information limits missing data, reduces potential confounding by missing data, and ensures high-quality data integrity. This study was carried out in a vulnerable population with risk factors of having a stroke (older adults with high burden of risk factors).

A potential weakness is that the outcome requires recognition of stroke signs in order to take the correct action. So we don't know if patients recognize stroke signs and don't call or whether they don't recognize the signs at all; in this respect, we have data to suggest that the gap might be in the area of identifying stroke signs.

We only evaluated a single 'outpatient clinic', insured under INSSJP in Buenos Aires City. However, we believe that although it represents the population, it cannot be generalized to the entire elderly population.

\section{Next Steps}

Education on acute stroke signs and symptoms is necessary to decrease pre-hospital delays and increase the number of patients who seek for emergency care.

Public awareness campaigns failed to improve population knowledge of stroke [28], risk factors, and warning signs $[28,29]$, and have no sustained effect over time [29, 30].

We believe that a 3-minute intervention where the primary care physician can provide information to patients with at least one stroke risk factor, about 'appropriate behavior in front of signs of stroke' will be of great help to the patients. This intervention might be delivered at a relatively low cost with a potential high impact in disability and mortality. Nonetheless, interventions would have to be tested to demonstrate efficacy and effectiveness.

\section{Conclusion}

These results show that stroke knowledge and endorsement to call emergency service are generally poor; this therefore emphasizes the need to educate the elderly population specifically about stroke.

\section{Acknowledgments}

We thank David Au and Cecilia Patiño from The American Thoracic Society (ATS) Methods in Epidemiologic, Clinical, and Operations Research (MECOR) Program; for reviewing the manuscript; and the students of the school of Medicine of the University of Buenos Aires, for the data collection.

We thank Susan Billings-Gagliardi, lead author of STAT original publication, for allowing us to conduct cultural adaptation of the questionnaire into Spanish.

\section{Disclosure Statement}

The authors have no conflicts of interest to disclose.

\section{References}

1 Roger VL, Go AS, Lloyd-Jones DM, Benjamin EJ, Berry JD, Borden WB, Bravata DM, Dai S, Ford ES, Fox CS, Fullerton HJ, Gillespie C, Hailpern SM, Heit JA, Howard VJ, Kissela BM, Kittner SJ, Lackland DT, Lichtman JH, Lisabeth LD, Makuc DM, Marcus GM, Marelli A, Matchar DB, Moy CS, Mozaffarian D, Mussolino ME, Nichol G, Paynter NP, Soliman EZ, Sorlie PD, Sotoodehnia N, Turan TN, Virani SS, Wong ND, Woo D, Turner MB: Heart disease and stroke statistics - 2012 update: a report from the American Heart Association. Circulation 2012;125:e2e220.

$\checkmark 2$ Murray CJ, Lopez AD: Measuring the global burden of disease. N Engl J Med 2013;369: 448-457.
3 Sposato LA, Esnaola MM, Zamora R, Zurru MC, Fustinoni O, Saposnik G: Quality of ischemic stroke care in emerging countries: the Argentinian National Stroke Registry (ReNACer). Stroke 2008;39:3036-3041.

$\checkmark 4$ Tissue plasminogen activator for acute ischemic stroke. The National Institute of Neurological Disorders and Stroke rt-PA Stroke Study Group. N Engl J Med 1995;333:1581-1587.

5 Furlan A, Higashida R, Wechsler L, Gent M, Rowley H, Kase C, Pessin M, Ahuja A, Callahan F, Clark WM, Silver F, Rivera F: Intraarterial prourokinase for acute ischemic stroke. The PROACT II study: a randomized controlled trial. Prolyse in Acute Cerebral Thromboembolism. JAMA 1999;282:20032011.
6 Hacke W, Kaste M, Bluhmki E, Brozman M, Davalos A, Guidetti D, Larrue V, Lees KR, Medeghri Z, Machnig T, Schneider D, von Kummer R, Wahlgren N, Toni D: Thrombolysis with alteplase 3 to 4.5 hours after acute ischemic stroke. N Engl J Med 2008;359:1317-1329.

-7 Saver JL, Jahan R, Levy EI, Jovin TG, Baxter B, Nogueira RG, Clark W, Budzik R, Zaidat OO: Solitaire flow restoration device versus the Merci Retriever in patients with acute ischaemic stroke (SWIFT): a randomised, parallel-group, non-inferiority trial. Lancet 2012;380:1241-1249.

8 Moradiya Y, Crystal H, Valsamis H, Levine SR: Thrombolytic utilization for ischemic stroke in US hospitals with neurology residency program. Neurology 2013;81:1986-1995. 
$\$$ Addo J, Ayis S, Leon J, Rudd AG, McKevitt C, Wolfe CD: Delay in presentation after an acute stroke in a multiethnic population in South London: the South London stroke register. J Am Heart Assoc 2012;1:e001685.

10 California Acute Stroke Pilot Registry (CASPR) Investigators: Prioritizing interventions to improve rates of thrombolysis for ischemic stroke. Neurology 2005;64:654-659.

11 Morris DL, Rosamond W, Madden K, Schultz C, Hamilton S: Prehospital and emergency department delays after acute stroke: the $\mathrm{Ge}$ nentech Stroke Presentation Survey. Stroke 2000;31:2585-2590.

12 Lylyk P: Encuesta: Señales de alerta del ACV. Intramed website, 2011. http://www.intra med.net/ira.asp? contenidoID $=73314$ (accessed February 15, 2013)

-13 Ferris A, Robertson RM, Fabunmi R, Mosca L: American Heart Association and American Stroke Association national survey of stroke risk awareness among women. Circulation 2005; 111:1321-1326.

14 Kim JS, Yoon SS: Perspectives of stroke in persons living in Seoul, South Korea. A survey of 1000 subjects. Stroke 1997;28:1165-1169.

15 Lundelin K, Graciani A, Garcia-Puig J, Guallar-Castillon P, Taboada JM, Rodriguez-Artalejo F, Banegas JR: Knowledge of stroke warning symptoms and intended action in response to stroke in Spain: a nationwide population-based study. Cerebrovasc Dis 2012; 34:161-168

16 Pancioli AM, Broderick J, Kothari R, Brott T, Tuchfarber A, Miller R, Khoury J, Jauch E: Public perception of stroke warning signs and knowledge of potential risk factors. JAMA 1998;279:1288-1292.
17 Ramsden VR, Shuaib A, Reeder BA, Khan K, Liu L: Risk factor awareness: a randomized telephone survey of public knowledge. Can J Public Health 1994;85(suppl 2):S57-S60.

18 Sug Yoon S, Heller RF, Levi C, Wiggers J, Fitzgerald PE: Knowledge of stroke risk factors, warning symptoms, and treatment among an Australian urban population. Stroke 2001;32:1926-1930.

19 Ellis C, Barley J, Grubaugh A: Poststroke knowlegde and symtoms awareness: a global issue for secondary stroke prevention. Cerebrovasc Dis 2013;35:572-581.

20 Billings-Gagliardi S, Mazor KM: Development and validation of the stroke action test. Stroke 2005;36:1035-1039.

21 Arribas A: Adaptación transcultural de instrumentos. Guía para el proceso de validación de instrumentos de tipo encuestas. Rev Asoc Méd Bahía Blanca 2006;16:74-82.

22 Goldstein LB, Adams R, Becker K, Furberg CD, Gorelick PB, Hademenos G, Hill M, Howard G, Howard VJ, Jacobs B: Primary prevention of ischemic stroke: a statement for healthcare professionals from the Stroke Council of the American Heart Association. Circulation 2001;103:163-182.

23 Ferrante D, Virgolini M: Encuesta Nacional de Factores de Riesgo 2005: resultados principales: prevalencia de factores de riesgo de enfermedades cardiovasculares en la Argentina. Rev Argent Cardiol 2007;75:20-29.

24 Adimark: El Nivel Socio Económico Esomar Manual de Aplicación Secondary El Nivel Socio Económico Esomar Manual de Aplicación. Microweb website, 2000. http://www. microweb.cl/idm/documentos/ESOMAR. pdf (accessed January 20, 2013).
25 La determinación del nivel socioeconómico de los hogares como base para segmentar la potencial demanda de viviendas. Gobierno del Chubut website, 2005. http://www.estadistica. chubut.gov.ar/home/archivos/publicaciones/ documentosTrabajo/nivel socioeconomico de los hogares.pdf (accessed January 20, 2013).

26 Miyamatsu N, Okamura T, Nakayama H, Toyoda K, Suzuki K, Toyota A, Hata T, Hozawa A, Nishikawa T, Morimoto A, Ogita M, Morino A, Yamaguchi T: Public awareness of early symptoms of stroke and information sources about stroke among the general Japanese population: the Acquisition of Stroke Knowledge Study. Cerebrovasc Dis 2013;35:241-249.

27 Mikulik R, Bunt L, Hrdlicka D, Dusek L, Vaclavik D, Kryza J: Calling 911 in response to stroke: a nationwide study assessing definitive individual behavior. Stroke 2008;39:1844-1849.

28 Mikulik R, Goldemund D, Reif M, Brichta J, Neumann J, Jarkovský J, Krýza J: Calling 911 in response to stroke: no change following a four-year educational campaign. Cerebrovasc Dis 2011;32:342-348.

29 Kleindorfer D, Khoury J, Broderick JP, Rademacher E, Woo D, Flaherty ML, Alwell K, Moomaw CJ, Schneider A, Pancioli A: Temporal trends in public awareness of stroke: warning signs, risk factors, and treatment. Stroke 2009;40:2502-2506.

30 Mellon L, Hickey A, Doyle F, Dolan E, Williams D: Can a media campaign change health service use in a population with stroke symptoms? Examination of the first Irish stroke awareness campaign. Emerg Med J 2013, Epub ahead of print. http://emj.bmj.com/content/ early/2013/07/26/emermed-2012-202280 (accessed December 14, 2013). 